\title{
Pre-Loading of Chlorophyll Synthase with Tetraprenyl Diphosphate Is an Obligatory Step in Chlorophyll Biosynthesis
}

\author{
Heidi C. Schmid ${ }^{1}$, Valentina Rassadina², Ulrike \\ Oster ${ }^{1}$, Siegrid Schoch ${ }^{1}$ and Wolfhart Rüdiger ${ }^{1, *}$ \\ ${ }^{1}$ Botanisches Institut, Ludwig-Maximilians-Universität \\ München, Menzingerstr. 67, D-80638 München, \\ Germany \\ ${ }^{2}$ Institute of Photobiology of the National Academy of \\ Science of Belarus, 220072 Minsk, Belarus \\ ${ }^{*}$ Corresponding author
}

The reaction of recombinant chlorophyll synthase from Avena sativa, expressed in Escherichia coli, was investigated. To verify the identity of the recombinant and native enzymes, reaction rates were determined for both enzyme preparations with several chlorophyllide analogs. The rates of esterification of these modified substrates ranged from 0 to $100 \%$ of the rate with the natural substrate, and were nearly identical for both enzyme preparations. The LineweaverBurk plot for variation of both chlorophyllide $a$ and phytyl diphosphate concentration showed parallel lines, indicative of a 'ping-pong' mechanism. Pre-incubation with phytyl diphosphate exhibited an initial rapid reaction phase, which did not occur after preincubation with chlorophyllide. We conclude that the tetraprenyl diphosphate must bind to the enzyme as the first substrate and esterification occurs when this pre-loaded enzyme meets the second substrate, chlorophyllide. Approximately $10-17 \%$ of the recombinant enzyme were pre-loaded with phytyl diphosphate under the experimental conditions. The rapid reaction phase is also observed for the chlorophyll synthase reaction in etiolated barley leaves in addition to the well-known slow phase. This indicates that pre-loading of the enzyme with tetraprenyl diphosphate is also the basis for the reaction in vivo.

Key words: Chlorophyll biosynthesis/Ping-pong reaction mechanism/Prenylation reaction/

Zinc pheophorbides.

\section{Introduction}

The last steps of chlorophyll (Chl) biosynthesis have often been investigated during illumination of etiolated (darkgrown) angiosperm seedlings. Such seedlings completely lack $\mathrm{Chl}$ when grown in absolute darkness but, instead, accumulate small amounts of protochlorophyllide a (Pch- lide a), which needs only 3 further enzymatic steps to form Chl a. Pchlide $a$ is first transformed into chlorophyllide a (Chlide a) upon irradiation, in a reaction catalyzed by the light-dependent enzyme NADPH:protochlorophyllide oxidoreductase (POR; for reviews see Griffiths, 1991; Lebedev and Timko, 1998). The remaining two enzymes of this pathway are chlorophyll synthase and geranylgeranyl reductase. Chlorophyll synthase preferentially catalyzes the prenylation of Chlide with either geranylgeranyl diphosphate (GGPP) in etiolated seedlings (Schoch et al., 1977; Schoch, 1978) or with phytyl diphosphate (PhyPP) in green plants (Soll et al., 1983). Geranylgeranyl reductase catalyzes the reduction of 3 double bonds either of GGPP or of the geranylgeranyl moiety in the pigment (Keller et al., 1998). The end product of the action of all 3 enzymes is phytylated Chl a. It was recently demonstrated that after full photoconversion of Pchlide a in etiolated barley seedlings by a saturating flash of light, the prenylation of the newly formed Chlide a followed complex kinetics with a fast phase during which about $15 \%$ of the Chlide a was esterified within $10-15 \mathrm{~s}$, and a slow phase of about 30-60 min during which the rest of the Chlide a was esterified (Domanskii and Rüdiger, 2001). The molecular basis for the complexity of these kinetics has remained unclear.

Detailed investigations of the properties of chlorophyll synthase became feasible after demonstration that the bchG gene of Rhodobacter capsulatus encodes bacteriochlorophyll synthase (Bollivar et al., 1994), and the G4 gene (later named ChIG gene) of Arabidopsis thaliana encodes chlorophyll synthase (Gaubier et al., 1995). The recombinant enzyme, produced by expression of the bchG from $R$. capsulatus in Escherichia coli, specifically accepted bacteriochlorophyllide but not Chlide, while the analogous expression of the chlG gene from Synechococcus sp. PCC 6803 yielded a chlorophyll synthase which accepted Chlide but not bacteriochlorophyllide (Oster et al., 1997). The recombinant enzyme produced with the ChIG gene from $A$. thaliana accepted Chlide a and $b$ and showed a preference for GGPP rather than for PhyPP (Oster and Rüdiger, 1997). Cloning and heterologous expression of the ChIG gene from Avena sativa revealed essential Cys and Arg residues of the enzyme and a requirement for $\mathrm{Mg}^{2+}$ ions for activity (Schmid et al., 2001). In all these earlier studies, only the slow phase of esterification was detected and considered. Here we describe experimental conditions for occurrence of an additional fast initial phase of esterification with the recombinant enzyme from $A$. sativa, and we report results which 
allow conclusions to be drawn about the molecular basis for the complex kinetics observed in vivo.

\section{Results}

\section{The Esterification Assay}

In the standard assay for determination of chlorophyll synthase kinetics, the bacterial lysate was mixed with PhyPP and the desired amount of buffer, and the reaction started by addition of Chlide or its $\mathrm{Zn}$ analogs. The reac-

A

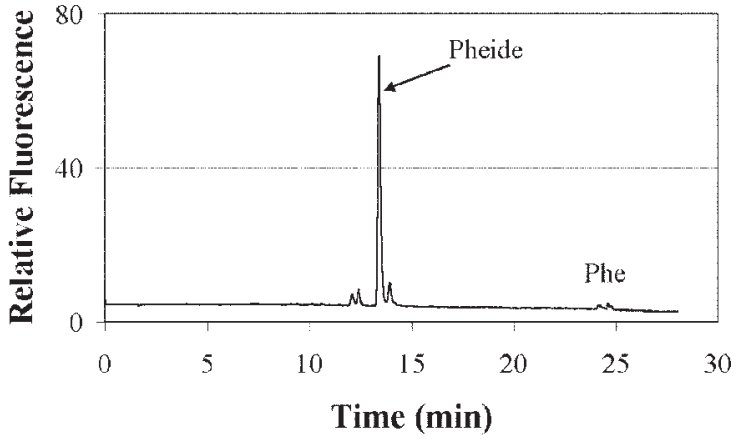

B

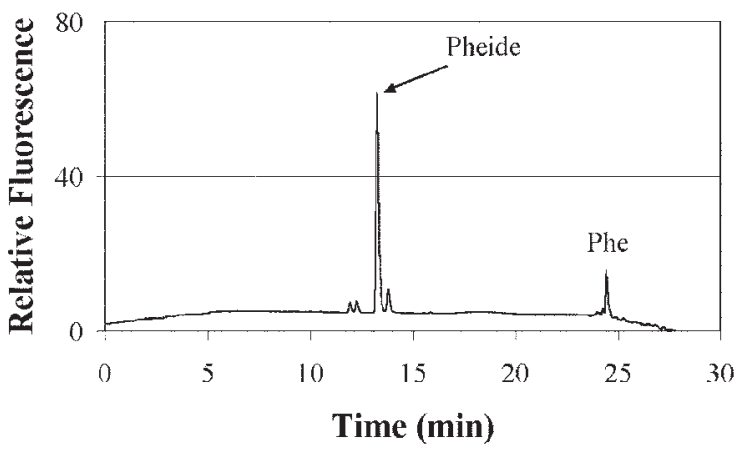

C

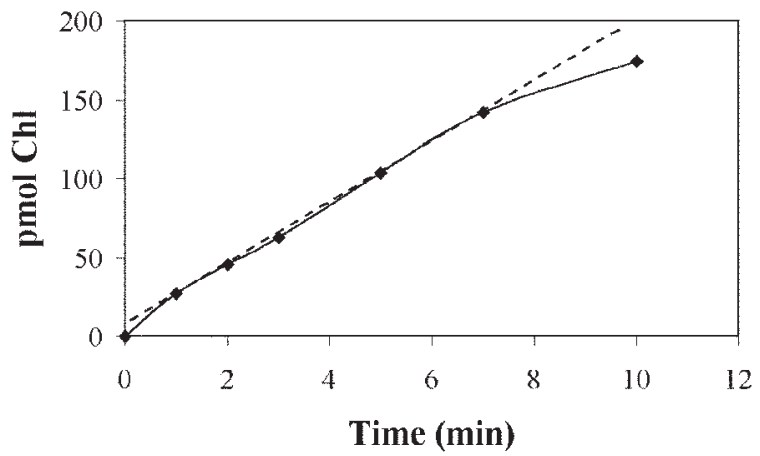

Fig. 1 Quantification of Esterified Chlorophyll by HPLC.

The examples shown were chlorophyll synthase reactions with $4.8 \mu \mathrm{m}$ Chlide and $40 \mu \mathrm{m}$ PhyPP. The amount of Phe was calculated from the ratio of esterified to non-esterified pigments. The incubation time was $1 \mathrm{~min}(\mathrm{~A})$ and $7 \mathrm{~min}(\mathrm{~B})$.

(C) The amount of Chl esterified in 1, 2, 3, 5, 7 and $10 \mathrm{~min}$. The slope (----) was determined from the linear part (1-7 $\mathrm{min})$; this slope was used for determination of kinetic data (see Figure 4). tion was stopped with acetone after specified periods, and the resulting pigment mixture was analyzed for total pigment by spectrophotometry and subsequently by HPLC using a fluorescence detector; this fluorescence assay is more sensitive than that using solvent extraction and absorption measurement as described by Helfrich et al. (1994). The sensitivity is especially important for the accurate pigment measurement at the beginning of the reaction, when very little esterified pigment is produced. Clear separation of the non-esterified pigments was obtained when the solvent system was slightly acidic: this caused partial removal of the central $\mathrm{Mg}$ ion. To completely remove $\mathrm{Mg}, \mathrm{HCl}$ was added to the pigment solution before injection into the HPLC system to analyze the metal-free pigments. In some experiments, traces of Mgcontaining pigments were still detected (see Figure $1 \mathrm{~A}$ and $B$ ): these were also included in the quantitative determination of pigments. The advantage of the solvent gradient used here is that both non-esterified and esterified pigments are determined in the same run (Figure $1 \mathrm{~A}$ and $B$ ). This not only allows the precise determination of the Pheide/Phe ratio but is also the basis for calculation of the absolute values of the esterified pigment in combination with the amount of total pigment (see above). The procedure excludes any pipetting errors during preparation of the HPLC probe. The reaction rate was determined using the linear part of the kinetics as shown for a typical experiment in Figure 1C. Depending on the substrate/enzyme ratio, the increase in product formation was linear with time for at least 7-10 min but extrapola-

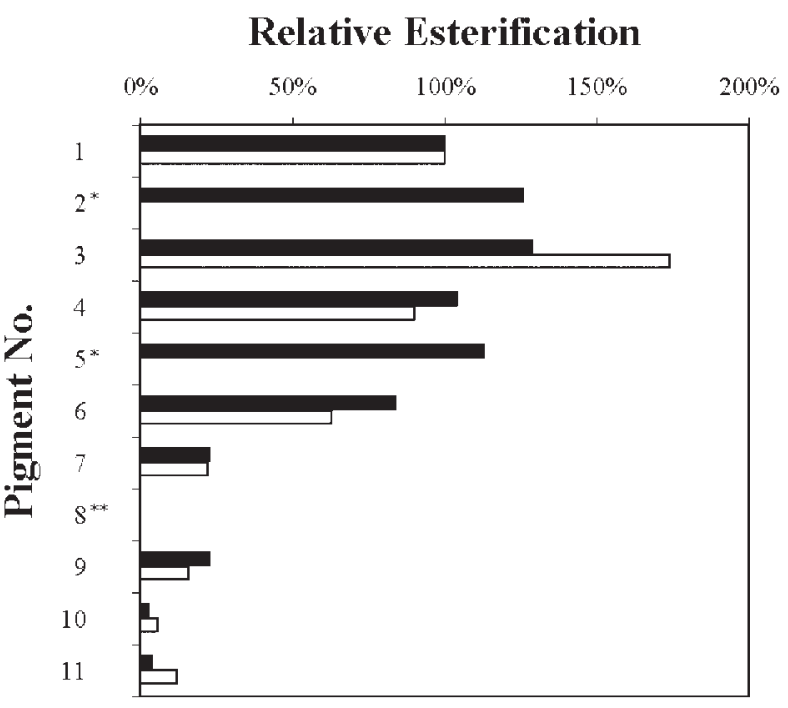

Fig. 2 Relative Chlorophyll Synthase Reaction Rates with Different Substrates.

The black bars indicate data obtained with the recombinant enzyme (this work), while the white bars were calculated from the data of Helfrich (1995) obtained with the native enzyme of oat etioplasts. The rate of esterification of $\mathrm{Zn}$ Pheide a was set at $100 \%$ with both enzymes.

*Esterification was only determined with the recombinant enzyme.

${ }^{\star *}$ No esterification with both enzymes. 
tion of the linear slope to time zero did not intersect the point of origin (this phenomenon will be discussed in detail in connection with data of Figures 5 and 6).

Previous investigations on chlorophyll synthase were performed with either geranylgeranyl diphosphate (GGPP) or phytyl diphosphate (PhyPP), which are both natural substrates. When $80 \mu \mathrm{M}$ GGPP was used, it was found that the reaction rate declined to zero already after 3-4 min. A second addition of GGPP resulted in further activity again for a period of 3-4 min (data not shown). Apparently, GGPP is rapidly metabolized in the bacterial lysate to a form which is no longer available for the chlorophyll synthase reaction. We confirmed this assumption by pre-incubation of the lysate with GGPP for 10 min before adding Chlide, and there was no esterification; however, the enzyme was still active as shown by resumption of esterification when GGPP was added. By contrast, PhyPP proved to be stable in the presence of the bacterial lysate, and the same linear progress of esterification occurred for about 7-10 min when Chlide was added at the same time or 10 min after PhyPP. For stability, all subsequent measurements were performed with PhyPP.

\section{The Recombinant and Native Chlorophyll Synthase Behave Similarly}

To test whether data obtained with the recombinant enzyme are relevant for the situation in vivo, we compared

$\mathbf{A}$

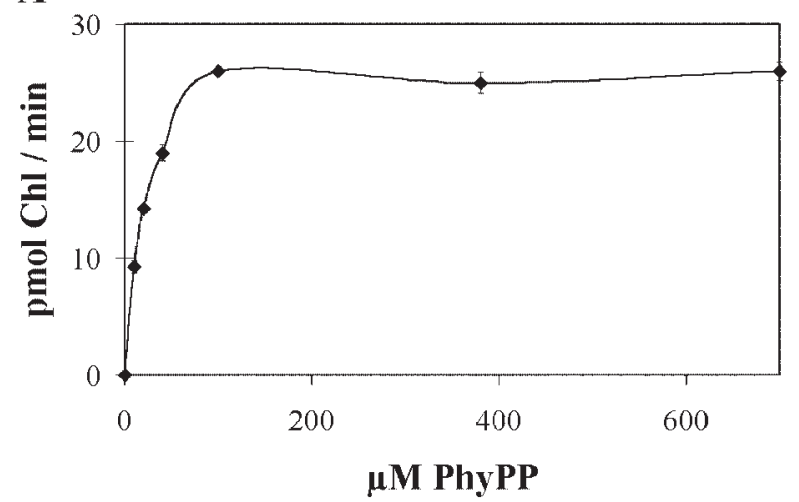

B

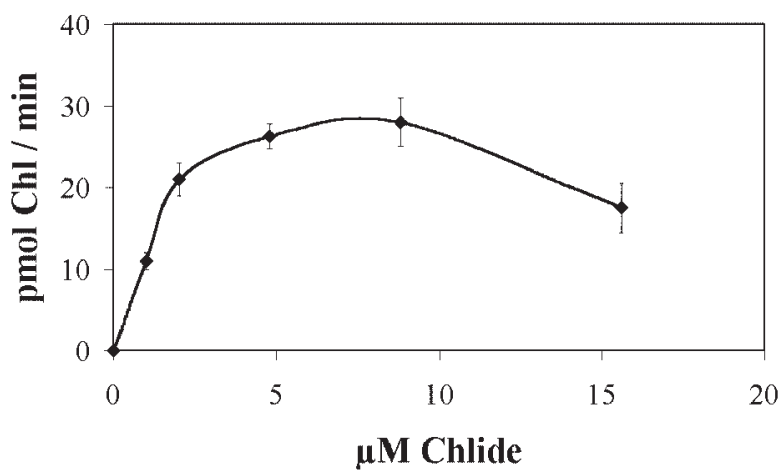

Fig. 3 Substrate Saturation in the Chlorophyll Synthase Assay. (A) Saturation of PhyPP at constant $4.8 \mu \mathrm{M}$ Chlide.

(B) Saturation of Chlide at constant $360 \mu \mathrm{M}$ PhyPP. the kinetics of the recombinant enzyme with that of the native enzyme (Figure 2). The source of the latter was a preparation of inner membranes of oat etioplasts (Helfrich et al., 1994). As substrates, several modified compounds (1-11) were added, some of which had already been shown to be more or less well accepted as substrates (Helfrich, 1995). Consistent with the results obtained with the native enzyme, esterification was faster with $\mathrm{Zn}$ Pheide $b$ (3) than with Zn Pheide a (1). Zn Pheide $d$ (2), which had not yet been tested with the native enzyme, also showed a faster reaction than 1 . The esterification rate of $\mathrm{Zn} 7^{1}-\mathrm{OH}-$ Pheide a (4) and of its pyro derivative 5 was about the same as that of 1, while Zn pyroPheide a (6) also reacted but more slowly. Esterification was significantly slower with the $13^{2}(S)$ methoxy compound 7 and the $13^{2}(R)$ pyro derivative 9 , while the $13^{2}(R)$ methoxy compound 8 was not accepted at all. Less reactivity than with 7 was found with the $13^{2}(S)$ ethoxy compound 10 and with Zn chlorin- $e_{6}$-dimethylester (11). Thus, the order of reac-
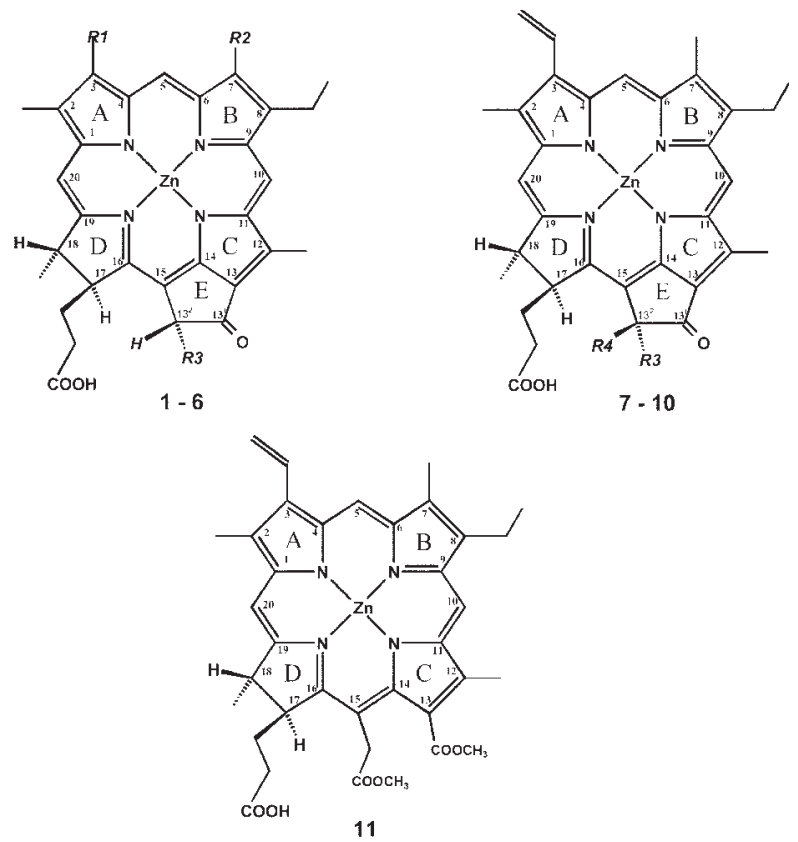

$\begin{array}{lll}\mathrm{R} 1 & \mathrm{R} 2 & \mathrm{R} 3 \\ \mathrm{CH}=\mathrm{CH}_{2} & \mathrm{CH}_{3} & \mathrm{COOCH}_{3} \\ \mathrm{CHO} & \mathrm{CH}_{3} & \mathrm{COOCH}_{3} \\ \mathrm{CH}=\mathrm{CH}_{2} & \mathrm{CHO} & \mathrm{COOCH}_{3} \\ \mathrm{CH}=\mathrm{CH}_{2} & \mathrm{CH}_{2} \mathrm{OH} & \mathrm{COOCH} \\ \mathrm{CH}=\mathrm{CH}_{2} & \mathrm{CH}_{2} \mathrm{OH} & \mathrm{H} \\ \mathrm{CH}=\mathrm{CH}_{2} & \mathrm{CH}_{3} & \mathrm{H}\end{array}$

R3

R4

$\mathrm{COOCH}_{3} \quad \mathrm{OCH}_{3}$ $\mathrm{OCH}_{3} \quad \mathrm{COOCH}_{3}$ $\mathrm{OCH}_{3} \quad \mathrm{H}$ $\mathrm{COOCH}_{3} \quad \mathrm{OC}_{2} \mathrm{H}_{5}$ 
A

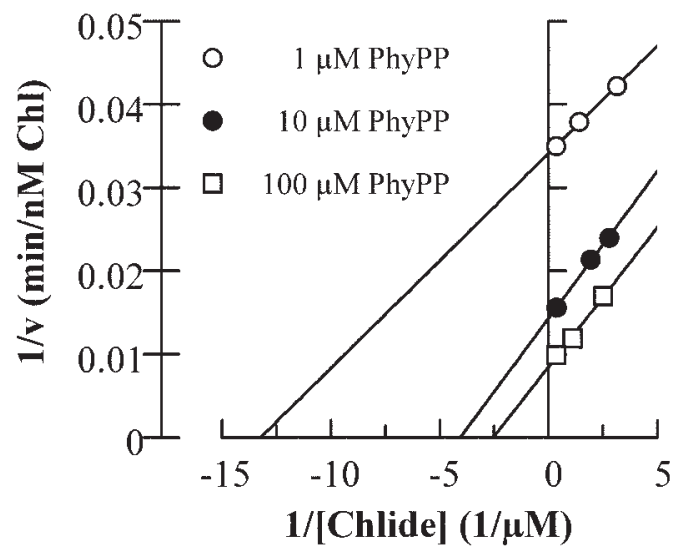

B

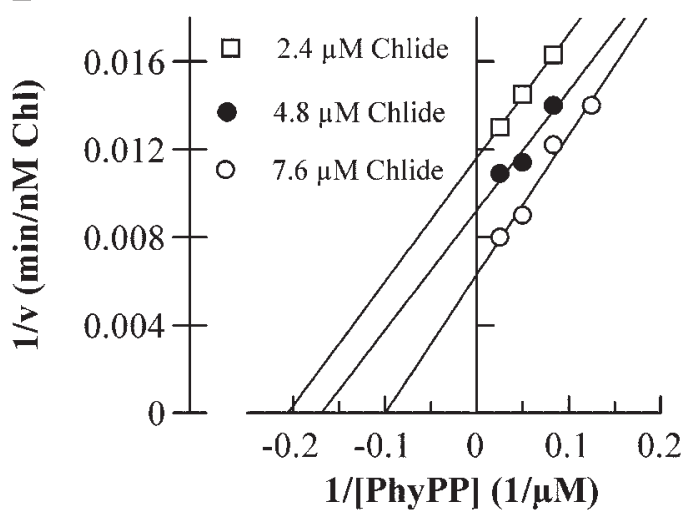

Fig. 4 Lineweaver-Burk Plots of the Chlorophyll Synthase Reaction.

(A) Dependence of the reaction rates on the concentration of Chlide at specified PhyPP concentrations. (B) Dependence of the reaction rates on the concentration of PhyPP at specified Chlide concentrations.

tivity of the substrates tested was the same for both the native and the recombinant chlorophyll synthase.

\section{The Reaction Follows a Ping-Pong Mechanism}

Preliminary studies of the change of esterification rate with substrate concentration, performed with the method of Helfrich et al. (1994), indicated a 'normal' saturation curve for PhyPP (Figure $3 \mathrm{~A}$ ) and the characteristic of substrate inhibition for Chlide (Figure 3B) with the optimum reaction rate occurring at 5-10 $\mu \mathrm{m}$ Chlide. The variation of substrate concentration in the following detailed investigation was therefore limited for Chlide up to about $8 \mu \mathrm{M}$, while a range up to $100 \mu \mathrm{m}$ was used for PhyPP. Surprisingly, the Lineweaver-Burk plots of the kinetics with varying concentrations of Chlide and three constant concentrations of PhyPP exhibited parallel, straight lines (Figure 4A). The same was true for varying concentrations of PhyPP and three constant concentrations of Chlide (Figure 4B). The non-intersecting lines of such plots are characteristic of a 'ping-pong' mechanism, which is defined by modification of the enzyme by the first substrate before reaction of the modified enzyme with the second substrate (Voet and Voet, 1990). To determine which substrate, PhyPP or Chlide, is the 'first' and 'second' substrate, the enzyme preparation was pre-incubated for 10 min with PhyPP and the reaction started with Chlide. The control experiment consisted of pre-incubation with Chlide and initiating the reaction with PhyPP. Pre-incubation with the correct 'first' substrate should result in formation of the modified enzyme and, if the modifying reaction is the time-limiting step, the first round of product formation corresponding to stoichiometric amounts of the modified enzyme should be faster than without preincubation. On the other hand, pre-incubation with the 'second' substrate would not result in modified enzyme formation and hence the same initial velocity of esterification would be observed as without pre-incubation. Several experiments with different enzyme concentrations showed clearly that the initial velocity was always

A

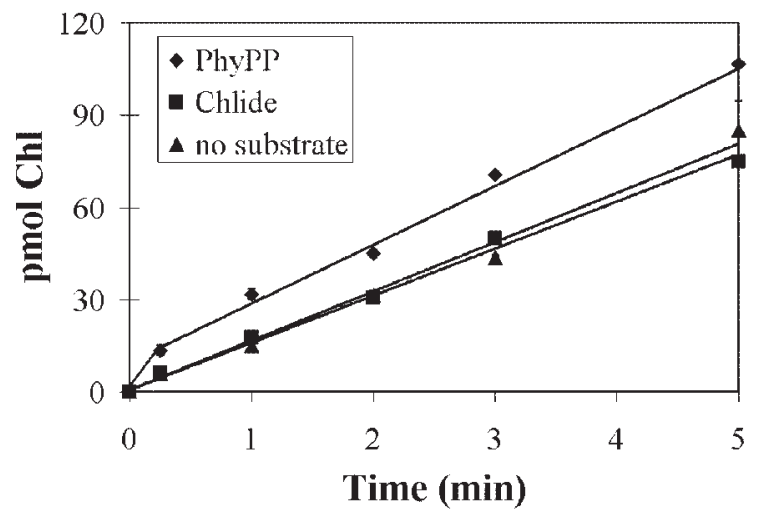

B

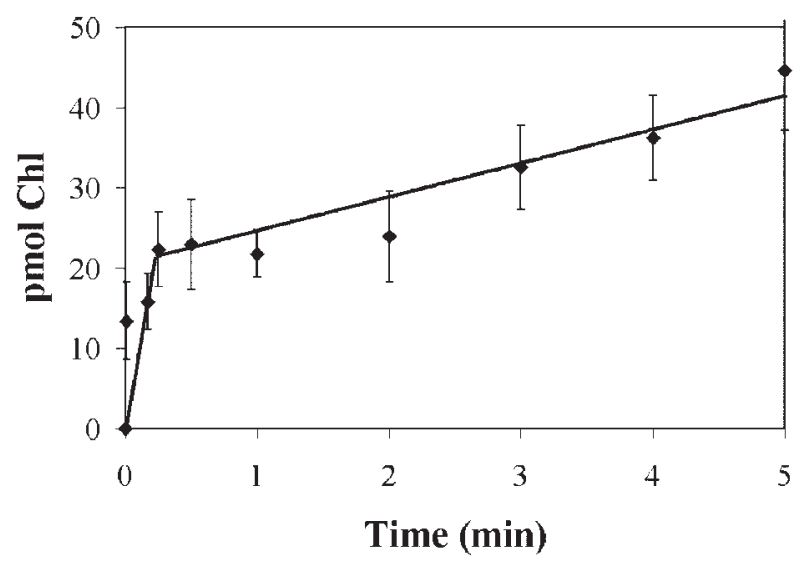

Fig. 5 Fast and Slow Phases of Esterification.

(A) Early kinetics of the reaction at $29^{\circ} \mathrm{C}$ with recombinant chlorophyll synthase after pre-incubation for $10 \mathrm{~min}$ with either buffer (no substrate), $360 \mu \mathrm{M}$ PhyPP or $6 \mu \mathrm{m}$ Chlide. The standard deviation is indicated $(n=3)$. Only pre-incubation with PhyPP leads to an increase in the initial esterification. (B) Early esterification kinetics with Hordeum vulgare seedlings. Segments of etiolated leaves were cut at $2 \mathrm{~cm}$ from the top and irradiated with a saturating flash and analyzed for Chl as described by Domanskii and Rüdiger (2001). The amount of Chl formed refers to one leaf segment. 
A

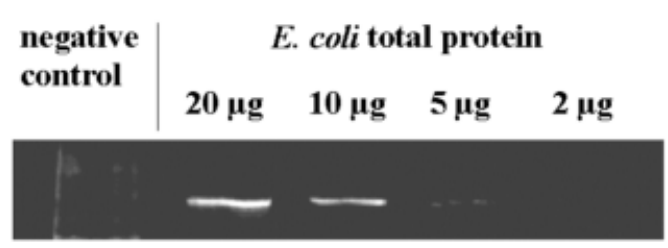

MBP (pure)

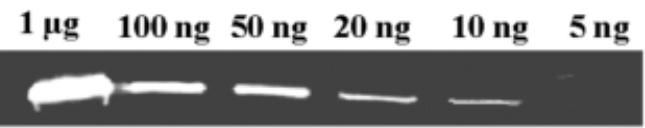

B

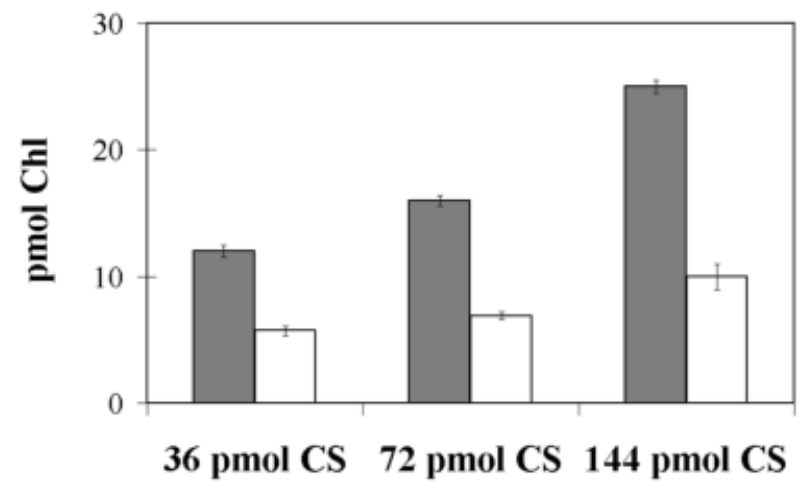

Fig. 6 Relationship between the Amount of Chlorophyll Synthase and Fast Esterification.

(A) Determination of the amount of the fusion protein MBP-chlorophyll synthase in the bacterial lysate. Upper panel: $E$. coli total protein, lower panel: pure MBP protein. Both lanes were stained with anti-MBP antibodies. The staining of total protein $(10 \mu \mathrm{g})$ corresponds to about $10 \mathrm{ng}$ of MBP protein. This also indicates the amount of chlorophyll synthase since the molecular mass of MBP approximately equals that of chlorophyll synthase. (B) Yield of Chl after reaction for $15 \mathrm{~s}$ with specified amounts of chlorophyll synthase (CS). The pre-incubation was carried out at room temperature for 10 min with $360 \mu \mathrm{m}$ PhyPP (gray columns) or $6 \mu \mathrm{m}$ Chlide (white columns), and the reaction started by adding $6 \mu \mathrm{m}$ Chlide or $360 \mu \mathrm{m}$ PhyPP. The standard deviation is indicated $(n=3)$. The difference between gray and white columns indicates the amount of Chl formed by the enzyme that was pre-loaded with PhyPP.

higher for the first $15-30 \mathrm{~s}$ of the reaction when the membrane preparation had been pre-incubated with PhyPP (the correct 'first' substrate) than after pre-incubation with Chlide (the correct 'second' substrate) or without pre-incubation (Figure 5A). Variation of the preincubation time with PhyPP from 5 to 20 min did not significantly alter the fast phase of the reaction; therefore, we used $10 \mathrm{~min}$ as the standard pre-incubation period. The observed fast reaction phase supports the proposed 'ping-pong' mechanism of the enzyme reaction and further indicates that PhyPP is the correct 'first' substrate, which is pre-loaded and thus modifies the enzyme.
The relevance for the situation in vivo was demonstrated by the analogous investigation of esterification in intact leaves. For this experiment, leaves of dark-grown (etiolated) barley seedlings were flash irradiated to convert protochlorophyllide $a$ that had accumulated in darkness to Chlide $a$, the substrate for chlorophyll synthase. The kinetics of formation of chlorophyll were analyzed at the same time scale as for the in vitro experiments (Figure $5 \mathrm{~B}$ ). The resemblance with the in vitro experiment after pre-incubation with PhyPP is obvious: a rapid phase of esterification is followed by a slower phase. Extrapolation of the linear slope indicates that the fast phase ends about $15-30 \mathrm{~s}$ after the flash.

\section{Experiments with a Fusion Protein of Chlorophyll Synthase and Maltose-Binding Protein}

The extent of esterification during the initial fast phase relative to that during the subsequent slow phase is apparently higher in the leaves than in the in vitro experiments. This could be caused by a different ratio of enzyme to tetraprenyl diphosphate. To test this hypothesis, we performed pre-incubation experiments with varying amounts of enzyme (Figure 6). These experiments were performed with a fusion protein of the maltose-binding protein and chlorophyll synthase (MBP-HCS). Control experiments verified that the fusion protein MBP-HCS exhibited the same enzyme kinetics as chlorophyll synthase alone (data not shown). MBP-HCS was quantified using anti-MBP antibodies as shown in Figure 6A. As expected, the amount of $\mathrm{Chl}$ formed in the fast phase increased with increasing amounts of enzyme after pre-incubation with PhyPP (Figure 6B). This increase was larger than that observed in the controls that were pre-incubated with Chlide and showed, on addition of PhyPP, only the slow phase of esterification (Figure 6B). Comparison of the amount of enzyme with the amount of Chl formed in the fast phase indicated a ratio of about $6-9: 1$. This means that about $11-17 \%$ of the enzyme was pre-loaded with PhyPP under the experimental conditions.

Table 1 Enzyme Activity of Recombinant Chlorophyll Synthases Derived from Mutated Genes.

\begin{tabular}{ll}
\hline Mutation & $\%$ Activity \\
\hline N146A & 0 \\
D147A & 0 \\
D150A & 0 \\
D154A & 0 \\
R161A & 0 \\
R161K & 34 \\
R161H & 1 \\
\hline
\end{tabular}

The mutation of the chlorophyll synthase gene from $A$. sativa is indicated as exchange of the resulting amino acid in the enzyme. The enzymatic activity was determined using the recombinant enzyme with Chlide $a$ and PhyPP and the product formation within 45 min was taken as activity. All values are in percent activity of the wild-type enzyme $=100 \%$. 


\section{Site-Directed Mutagenesis Reveals Essential Aspartate and Asparagine Residues}

Schmid et al. (2001) suggested a region including amino acid residues 138 to 160 in chlorophyll synthase of $A$. sativa as a binding region for the polyprenyl diphosphate in analogy to the homologous sequence in various polyprenyl transferases (Lopez et al., 1996), and in particular the possibilities of ionic interaction of the negatively charged diphosphate group with either Arg or Lys residues like in protein farnesyltransferase (Kral et al., 1997) or with Asp residues complexed with $\mathrm{Mg}^{2+}$ ions like in isoprenyl diphosphate synthases (Tarshis et al., 1996; Wang and Ohnuma, 1999). To test the probability of these hypotheses, we constructed point mutations in this region of $A$. sativa chlorophyll synthase and determined the activity of these variant enzymes (Table 1).

The amino acid residues Asn-146, Asp-147, Asp-150 and Asp-154 turned out to be essential for activity since no esterification was observed when one of these amino acids was replaced by Ala. This result supports the idea of diphosphate binding via complexed $\mathrm{Mg}^{2+}$; the original consensus sequence DDXXD (Tarshis et al., 1996) would be modified to NDXXD, in this case implying amino acid residues 146 through 150. The consensus motif must probably be extended to $D-154$ since an additional $D$ at this position is present in chlorophyll synthases, bacteriochlorophyll synthases and several polyprenyltransferases (see Discussion). Arg-151, which is located within the putative binding region, is not essential since its replacement by Ala still gives residual activity of chlorophyll synthase (Schmid et al., 2001). We confirmed that changing Arg-161 to the neutral amino acid Ala results in complete loss of activity; the positive charge turned out to be essential for enzyme activity since mutation to Lys yielded a reasonably active chlorophyll synthase, and even mutation to His gave still measurable activity (Table 1).

\section{Discussion}

Since esterification of Chlide does not change the UV/Vis absorption or fluorescence properties of the pigment, direct optical assays for the progress of the reaction are excluded. A dramatic decrease in polarity on esterification, however, permits a simple procedure of product extraction into n-hexane (see Helfrich et al., 1994) which has been used in most previous work (Oster et al., 1997; Oster and Rüdiger 1997; Schmid et al. , 2001) and also in the experiments described in Figures 3 and $5 \mathrm{~B}$ of this report. The main experiments of the present paper were performed, however, with the more sensitive method of HPLC analysis which allows quantification of as little as 20 pmol pigment and is linear up to 2500 pmol.

Chlorophyll synthase is an intrinsic membrane protein in which nine membrane-spanning helices have been predicted on the basis of the amino acid sequence (Schmid et al., 2001). According to activity measure- ments, native chlorophyll synthase is localized specifically in the inner membranes of plastids (Soll et al., 1983; Lindsten et al., 1990). It was not clear initially whether the recombinant enzyme folds correctly in the membrane system of Escherichia coli. The present work demonstrates parallel scales of acceptance of modified substrates by native and recombinant enzymes indicating that the folding of the active center, at least, is identical in both enzyme preparations; thus, the kinetic data obtained with the recombinant enzyme can be expected to be relevant also for the native enzyme.

The experiments with modified substrates show a wide range of acceptance which allow already some conclusions on the steric requirements of chlorophyll synthase. It had already been demonstrated that the enzyme does not accept $\mathrm{Chl} \mathrm{a}^{\prime}$, and steric constraint was assumed to be responsible (Helfrich et al., 1994) as confirmed by the present work. It is critical that the substituent at $\mathrm{C}-13^{2}$ on the same side of the tetrapyrrole ring as the 17-propionic acid side chain is a proton as in Chlide $a$, the natural substrate of chlorophyll synthase. Replacement of the proton by a methoxy group (compound 7) diminishes the reactivity, and compound 10 with an ethoxy group has even lower reactivity (see Figure 2). In Chlide $a^{\prime}$, the proton is replaced by the large methoxycarbonyl group and there is absolutely no reactivity. By contrast, the size of the substituent at $\mathrm{C}-13^{2}$ on the opposite side of the tetrapyrrole ring, which is the methoxycarbonyl group in Chlide $a$, does not play an essential role. When this group in Chlide $a$ and $\mathrm{Zn}$ Pheide $a$ is replaced by a methoxy group (compound 9) or by a proton (compound 6), reactivity does not significantly change. It is not self-evident that replacement of a large residue by a smaller group in a natural substrate must be tolerated by its enzyme since replacement of the $13^{2}-$ methoxycarbonyl group by a proton in protochlorophyllide leads to complete loss of reactivity with NADPH:protochlorophyllide oxidoreductase (Helfrich et al., 1996). Thus the methoxycarbonyl group must play a specific role in NADPH:protochlorophyllide oxidoreductase while the results obtained with chlorophyll synthase can be explained by steric constraint around the binding site at C$13^{2}$ of the substrate. Surprising, however, is the reactivity of $\mathrm{Zn}$ chlorin- $\mathrm{e}_{6}$-dimethylester (11), a compound without the isocyclic ring: the side chains at $\mathrm{C}-13$ and $\mathrm{C}-15$ of 11 must be flexible enough to accommodate the compound in the active center. The polarity of the substituent at C-7 does not play a major role since $\mathrm{Zn}$ Pheide $a, \mathrm{Zn}$ Pheide $b$ and $\mathrm{Zn} 7^{1}-\mathrm{OH}-$ Pheide $a$ are accepted almost equally as substrates for chlorophyll synthase. Whether or not the substituent at C-7 forms direct contacts with amino acids of the active center is still not known.

Domanskii and Rüdiger (2001) described a fast and a slow phase of esterification of Chlide $a$ in vivo when the reaction was started in etiolated barley leaves by a flash of light. The fast phase is completed within $15 \mathrm{~s}$ after the flash. We have shown here that the same type of kinetics can be obtained in vitro by pre-incubating chlorophyll 
synthase with PhyPP and starting the reaction by addition of Chlide (see Figure 5). It seems reasonable to assume that the conditions of the in vitro experiments match exactly those in vivo, since chlorophyll synthase and PhyPP (or GGPP) are present and probably in contact for a long period of time in etiolated plants. This situation corresponds to pre-incubation in vitro and should lead to pre-loading of the enzyme. Formation of Chlide a by the light flash corresponds to addition of Chlide in vitro, and the fast reaction is probably the first round of reaction with the pre-loaded enzyme. The reaction rate during this phase is determined only by the diffusion of Chlide as the second substrate.

This assumption predicts that the amount of $\mathrm{Chl}$ formed in the fast phase equals the amount of pre-loaded enzyme. Due to lack of antibodies directed against chlorophyll synthase, the amount of enzyme cannot yet be determined in vivo. For the in vitro experiments, we selected a slightly indirect method of determination. We created the fusion protein MBP-HCS, in which the maltose-binding protein (size $42.5 \mathrm{kDa}$ ) and chlorophyll synthase (size $41.5 \mathrm{kDa}$ ) are linked in a 1:1 ratio. The quantification by anti-MBP antibodies, calibrated with authentic maltose-binding protein, gives at the same time the amount of MBP and of chlorophyll synthase in the fusion protein (see Figure 6). The amount of chlorophyll synthase is 5- to 10-fold higher than the amount of Chl produced in the fast phase and is consistent with the fast phase being the first round of the enzyme reaction in which $11-17 \%$ of the enzyme is pre-loaded with PhyPP. The value of $11-17 \%$ pre-loading (see Results) is of course an approximation since determination of the enzyme protein via Western blotting yields only approximate values, while the Chl quantification method is precise. The calculation of the amount of Chl formed during the fast phase, however, suffers from some uncertainty because we chose a reaction time of $15 \mathrm{~s}$ for the determination of $\mathrm{Chl}$ (Figure $5 \mathrm{~B}$ ): in the (unlikely) case that the first round of reaction is of longer duration, our Chl values would be too small.

Pre-incubation with Chlide leads to 'normal' kinetics with a linear initial reaction rate starting at the point of origin (Figure 5A). The difference between the amount of Chl formed after pre-incubation with PhyPP minus the amount of Chl formed after pre-incubation with Chlide should be the amount of Chl formed from the pre-loaded enzyme and this difference would be constant with time if both reaction rates are identical after completion of the rapid phase. Figure 5A shows a slightly steeper slope for the kinetics after PhyPP pre-incubation than after Chlide pre-incubation, which possibly indicates a slight activation or stabilization of the enzyme so that the difference gets larger with time. Thus, our Chl values could be a little too large if the true fast phase is shorter than $15 \mathrm{~s}$.

An obvious observation, illustrated in Figure 6B, is the production of less than twice the amount of $\mathrm{Chl}$ when the amount of bacterial lysate is doubled. This effect is especially pronounced in the controls in which the reaction rate, according to the proposed ping-pong mechanism, depends on diffusion and binding of both PhyPP and Chlide, and it is less pronounced in the samples that were pre-incubated with PhyPP in which the initial reaction rate depends only on the diffusion and binding of Chlide. The ping-pong mechanism implies that binding of the first substrate leads to modification, most probably including a conformational change, of the enzyme. The high viscosity of the membrane suspension with up to $24 \mathrm{mg}$ total protein per $\mathrm{ml}$ could slow down the diffusion of the substrates and, in particular, retard conformational changes caused by PhyPP binding. This assumption could explain why the activity responds more to viscosity when PhyPP binding is still involved than after pre-incubation with PhyPP.

Lopez et al. (1996) pointed out that chlorophyll and bacteriochlorophyll synthases are evolutionary related to a group of polyprenyltransferases, which are intrinsic membrane proteins and are involved in biosynthesis of menaquinone (MenA gene) and ubiquinone (ubiA and COQ2 genes). The latter are now known to be members of the UbiA prenyltransferase family that includes in addition enzymes catalyzing farnesylation of protoheme (cyoE, ctaB, and COX10 genes).The members of the UbiA family are known to be membrane bound with predicted 6-9 transmembrane segments, depending on the program used for prediction. The best conserved region, supposed to be the binding site for polyprenyl diphosphate (Melzer and Heide, 1994), is located in the loop between the second and third transmembrane segment (see Figure 7) and has been used as signature pattern for this family of proteins (see Table 2). Lopez et al. (1996) fa-

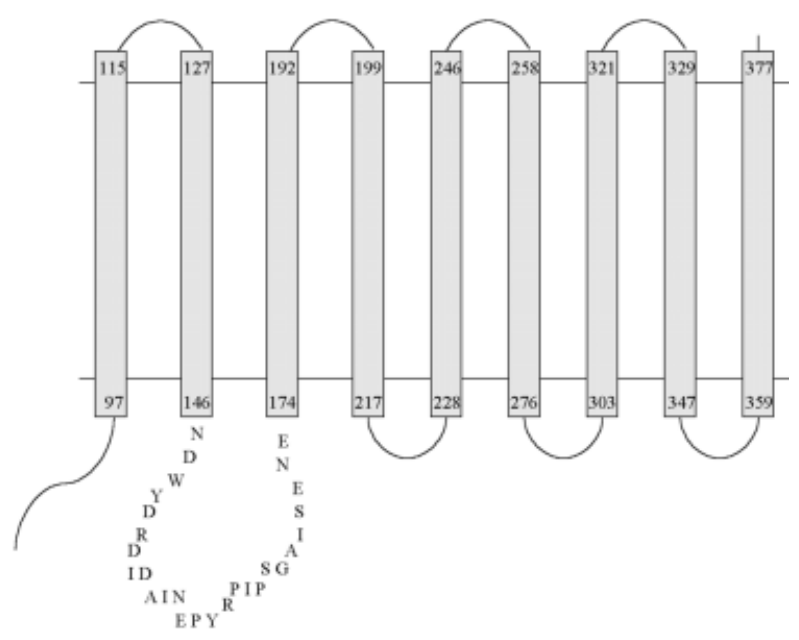

Fig. 7 Secondary Structure Prediction of Chlorophyll Synthase and Related Prenyltransferases.

The columns indicate the transmembrane segments, predicted by the program HMMTOP for the prenyltransferases summarized in Table 2, and the numbers indicate the position of amino acid residues in the oat sequence. The amino acids of the loop between transmembrane segments II and III are given for the oat sequence, and the consensus sequences of Table 2 are contained in this loop. 
Table 2 Signature Pattern of Prenyltransferases.

\begin{tabular}{|c|c|c|c|}
\hline Subclass & $\begin{array}{l}\text { Accession number } \\
\text { of type enzyme }\end{array}$ & $\begin{array}{l}\text { Number of } \\
\text { homologs }\end{array}$ & Consensus sequence \\
\hline \multirow[t]{2}{*}{ Chl-S } & Q9M3W5 & 12 & NDXXDRxVDAINEP $x--R P I P x G$ \\
\hline & & & A I $\quad$ D $\quad$ LCA \\
\hline Toc-PT & AAL35412 & 5 & NQxxDxxIDKxNKP $x^{--L P x A x G}$ \\
\hline \multirow[t]{2}{*}{$\mathrm{HB}-\mathrm{PT}$} & Q10252 & 46 & NDxxDxxxDxxVxRTxxRxxxxG \\
\hline & & & $\mathrm{D} \quad \mathrm{N}$ \\
\hline \multirow[t]{2}{*}{ Heme-FT } & P21592 & 27 & NxxxDxxxDxxMxRTxxRPxxxG \\
\hline & & & $\begin{array}{ll}\mathrm{E} & \mathrm{V}\end{array}$ \\
\hline \multirow[t]{4}{*}{ UbiA } & signature & & NxxxDxxLDxxVxRSxxRxxxxG \\
\hline & & & $\begin{array}{lllll} & E & I & M & T\end{array}$ \\
\hline & & & $\mathrm{H} \quad \mathrm{M}$ \\
\hline & & & $\mathrm{F}$ \\
\hline \multirow[t]{3}{*}{ New signature } & & & NxxxDxxxDxxVxPx--RxxxxG \\
\hline & & & $\begin{array}{llll}D & E & M & R\end{array}$ \\
\hline & & & $\mathrm{N}$ \\
\hline
\end{tabular}

Within each subclass of prenyltransferases, the sequence of the specified type enzyme was compared with those of related proteins found in SWISS-PROT ALL library with FASTA (version 3.3). The Table shows the consensus patterns of part of domain II, which is located in the loop between transmembrane segments II and III. Underlined are the amino acid residues that are exchanged to less than $10 \%$ of the specified sequences. For more than $10 \%$ exchange, the second and third amino acids are indicated below or, if there are more exchanges, the position is described by $\mathrm{x}$. The abbreviations are: Chl-S: chlorophyll and bacteriochlorophyll synthases; Toc-PT: tocopherol polyprenyltransferases; HB-PT: hydroxybenzoate poly- and octaprenyltransferases; Heme-FT: protoheme farnesyltransferases; UbiA: UbiA prenyltransferase family signature according to PROSITE file PDOC00727 (release of December 2001; http://www.expasy.ch/cgi-bin/).

vored the motif DRxxD (starting with D150 in chlorophyll synthase) for polyprenyl diphosphate binding while Schmid et al. (2001) pointed out that an overlapping motif NDxxD starting with N146 could also be a candidate. Here we demonstrated by site-directed mutagenesis of chlorophyll synthase that several amino acids in this region are essential for activity (see Table 1); the results can be summarized in form of the motif NDxxDxxxDxxxxxxR, starting with N146, where only the essential amino acid residues are named. This motif matches the signature of the ubiA family except for the position of R161, an Arg residue is found in the ubiA signature sequence only two positions later. The discrepancy, albeit minimal, prompted us to search for consensus sequences in the loop region of several subclasses of polyprenyltransferases. As shown in Table 2, each subclass has a particular consensus sequence. Since the probability to find the essential residues increases with the number of sequences considered, the future may reveal less essential residues than indicated here as true signature for Chl-S and TocPT of which only 13 and 6 sequences are available at present. The best alignment with the other subclasses is obtained when a gap of two residues is allowed for Chl-S and Toc-PT as shown in Table 2. Another gap of two more residues is required for all subclasses of Table 2 when also the MenA prenyltransferase family is to be included (not shown in Table 2). Nevertheless, there is no doubt about the evolutionary relationship of all subclasses compiled in Table 2, which follows also from the similarities in other regions of the entire sequence not further discussed here. In the putative binding region for the polyprenyl diphosphate, a new signature can be proposed for the extended family (see Table 2), and since this signature contains the Asn and Asp residues that are essential for enzyme activity and have been proposed to be essential for PhyPP binding of chlorophyll synthase (Schmid et al., 2001) it seems reasonable to suppose that the enzyme family shares not only binding of the substrate but also the reaction mechanism. Future investigations will reveal whether preloading with the polyprenyl diphosphate is required by all members of the extended UbiA family. It must be mentioned that the motif DDxxD as binding motif for prenyldiphosphate has also been found in farnesyldiphosphate and geranylgeranyldiphosphate synthases, which are not evolutionary related to the ubiA family (Wang and Ohnuma, 1999).

\section{Materials and Methods}

\section{Cloning and Expression of Chlorophyll Synthase}

The plasmid pQE60-HCS containing the 1428 bp full-length chlorophyll synthase gene (Schmid et al., 2001) was transformed into E. coli strain SG13009 (Qiagen, Hilden, Germany) and for 
overexpression, supermedium $(500 \mathrm{ml})$ containing $2.5 \%$ trypton/pepton, $1.5 \%$ yeast extract, $0.6 \% \mathrm{NaCl}$, ampicillin $(100 \mu \mathrm{g} / \mathrm{ml})$ and kanamycin $(25 \mu \mathrm{g} / \mathrm{ml})$ was inoculated with an overnight culture of the transformants. The expression was performed at room temperature. At an $\mathrm{OD}_{600}$ of 0.6 , the cells were induced with $0.3 \mathrm{~mm}$ IPTG and were grown for another $4 \mathrm{~h}$. The bacterial cells (containing a total of $250-300 \mathrm{mg}$ protein per $500 \mathrm{ml}$ of medium) were harvested by centrifugation ( $6000 \mathrm{~g}$ for $15 \mathrm{~min}$ ), washed with $15 \mathrm{ml} 50 \mathrm{~mm}$ HEPES (pH 8.0) and broken with a French Press (twice at $10^{8} \mathrm{~Pa}$ ).

In vitro mutagenesis was performed according to the 'quickchange' site-directed mutagenesis protocol (Stratagene, La Jolla, USA) using Pwo polymerase (Peqlab, Erlangen, Germany) and the restriction enzyme Dpnl (NEB, Schwalbach, Germany). The mutated plasmids were transformed into E. coli XL1 Blue cells and the mutations were verified by sequencing. Subsequent transformation into $E$. coli strain 13009 and expression were performed as described above. For fusion with the maltose-binding protein, the chlorophyll synthase gene was amplified with the primers p1 (5'-CGC GCG TGA TCA ATG GCC ACC TCC CAC CCT-3') containing a Bc/l restriction site and p2 (5'CGC ATA AGC TTC AAG GGG AAA CAA TTT G-3') containing a Hindlll restriction site using the plasmid PQE60-HCS as template. The resulting fragment was ligated into the vector pMal P2 (NEB) that had been restricted with BamHI and HindllI. The resulting plasmid was transformed into E. coli strain CAG 597 (NEB). The expression was performed at $30^{\circ} \mathrm{C}$, induction and lysis of the bacterial cells followed the above scheme.

\section{Enzyme Assay}

Aliquots of this bacterial lysate (containing a total of $3 \mathrm{mg}$ protein) were mixed with specified amounts of PhyPP as indicated in the various experiments and 50 mM HEPES buffer $(\mathrm{pH} 8.0)$ was added to a total volume of $250 \mu \mathrm{l}$. The reaction was started under dim-green safelight by addition of specified amounts of Chlide, or its $\mathrm{Zn}$ analogs, dissolved in acetone $(2-8 \mu \mathrm{l})$. Control experiments had shown that the reaction did not change upon addition of up to $15 \mu \mathrm{l}$ acetone. In some experiments, the bacterial lysate was pre-incubated with either PhyPP or Chlide for $10 \mathrm{~min}$ at room temperature and the reaction was started by addition of the missing substrate. After incubation for 1, 2, 3, 5 or $10 \mathrm{~min}$ at $29^{\circ} \mathrm{C}$, the reaction was stopped by addition of acetone $(750 \mu \mathrm{l})$, and the precipitated protein was removed by centrifugation (13 $000 \mathrm{~g}$ for $5 \mathrm{~min}$ ). The total content of esterified plus non-esterified pigment in the supernatant was determined spectrophotometrically using the absorption at $750 \mathrm{~nm}$ as the base line value to correct for nonspecific absorption and the following values for millimolar extinction coefficients at $\lambda_{\max }$ of the pigments: Chl(ide) a: 76.8 at 665 nm (Porra, 1991), Zn-Phe(ide) a: 77.3 at $660 \mathrm{~nm}$ (Jones et al., 1977), compounds 7, 8, and 10: 77.3 at $660 \mathrm{~nm}$ (Klement et al., 1999), compound 4: 65.7 at $655 \mathrm{~nm}$ (Klement et al., 1999), Zn-Pheide b: 51.3 at $642 \mathrm{~nm}$ (Jones et al., 1977), compound 11: 48.0 at $640 \mathrm{~nm}$ (calculated from the Mg-complex; Porra, 1991), Zn-Pheide d: 85 at $683 \mathrm{~nm}$ (calculated from the ratio for $\mathrm{Chl} d: \mathrm{Chl}$ a; Holt and Morley, 1959), compounds 6 and 9: 69 at $660 \mathrm{~nm}$ (calculated from the ratio for Chl a:pyro-Chl a; Pennington et al., 1964).

After addition of saturated $\mathrm{NaCl}(100 \mu l)$ to the acetone phase, the probes were extracted with ethyl acetate $(500 \mu \mathrm{l})$. Subsequent to centrifugation ( $13000 \mathrm{~g}$ for $5 \mathrm{~min}$ ), the upper phase was evaporated in a rotary evaporator and the residue stored at $-20^{\circ} \mathrm{C}$. For HPLC analysis, the pigments were dissolved in acetone $(35 \mu \mathrm{l})$ and $0.25 \mathrm{M} \mathrm{HCl}(10 \mu \mathrm{l})$ and $20 \mu \mathrm{l}$ were injected into a RP18 column (Grom, Herrenberg, Germany). The fluorimeter detector was set at $410 \mathrm{~nm}$ (excitation) and $670 \mathrm{~nm}$ (emission) for
Phe(ide) a, at 460 and $645 \mathrm{~nm}$ for Zn Phe(ide) $b$, at 400 and $635 \mathrm{~nm}$ for $\mathrm{Zn}$ chlorin- $\mathrm{e}_{6}$-dimethylester, and at 425 and $665 \mathrm{~nm}$ for the residual pigments (see Figure 2). The pigments were separated with the following elution program: 3 min $60 \%$ acetone, 20 min linear gradient to $100 \%$ acetone, 3 min $100 \%$ acetone. The doubly-distilled water used for the preparation of $60 \%$ acetone was adjusted to $\mathrm{pH} 3.5$ with acetic acid. The retention times of the unesterified and esterified pigments (Figure 2) are as follows: compound 1 (11.2 $\mathrm{min} / 21.7 \mathrm{~min}), 2$ (9.1 $\mathrm{min} / 20.9 \mathrm{~min}), 3$ (8.5 min/20.3 min), 4 (5.0 min/19.5 min), 5 (10.8 min/21.2 min), 6 (11.7 min/21.9 min), 7 (10.6 min/21.2 min), 8 (14.6 min/-), 9 (11.7 $\mathrm{min} / 21.9 \mathrm{~min}), 10$ (11.4 min/21.6 min), 11 (12.5 min/ $21.9 \mathrm{~min})$. The peaks were analyzed with Chromstar, version 4.08 (Gynkotek, Germering, Germany). The ratio of esterified to non-esterified pigments corresponds to the ratio of peak areas and this ratio together with the value of total pigments (see above) was used for calculation of the absolute amount of esterified pigments. Fitting and analysis of kinetic data was performed with GraFit, version 3.01 (Erithacus Software Ltd., Staines, UK). For the results in Figures 3 and $5 B$, the amount of $\mathrm{Chl}$ and Chlide after the enzyme assay was determined by phase separation and spectrophotometry (Helfrich et al., 1994; Schmid et al., 2001).

\section{Western Blot}

The bacterial lysate was solubilized in sample buffer $(0.6 \mathrm{M}$ Tris/ $\mathrm{HCl}$ containing $10 \%$ glycerol, $0.25 \%$ dithiothreitol, $1 \%$ sodium dodecylsulfate and $0.005 \%$ bromophenol blue). Aliquots of this solution containing a total of $2-20 \mu \mathrm{g}$ protein were applied to SDS-PAGE with $12 \%$ acrylamide as the separation gel and the separated proteins were blotted onto nitrocellulose with the semi-dry method (Kyhse-Anderson, 1984). Immunodetection was performed according to Beisiegl (1986): anti-MBP antibodies (NEB) were applied as the primary antibodies in a 1:10 000 dilution, followed by incubation with anti-rabbit IgG conjugated to alkaline phosphatase (No. A2556, Sigma, Taufkirchen, Germany) as the second antibody. The bands were then stained with $p$-nitro-blue-tetrazolium chloride and 5-bromo-4-chloro-3indolyl phosphate. For calibration, specified amounts (5 $\mathrm{ng}-1 \mu \mathrm{g}$ ) of authentic maltose-binding protein (NEB) were blotted and stained.

\section{Acknowledgements}

This work was supported by the Deutsche Forschungsgemeinschaft, Bonn, Germany. V. Rassadina thanks the Deutsche Akademische Austauschdienst, Bonn, for a travel grant.

\section{References}

Beisiegel, U. (1986). Protein blotting. Electrophoresis 7, 1-18. Bollivar, D. W., Wang, S., Allen, J. P., and Bauer, C. E. (1994). Molecular genetic analysis of terminal steps in bacteriochlorophyll a biosynthesis: characterization of a Rhodobacter capsulatus strain that synthesizes geranylgeraniol-esterified bacteriochlorophyll a. Biochemistry 33, 12763-12768.

Domanskii, V. P., and Rüdiger, W. (2001). On the nature of the two pathways in chlorophyll formation from protochlorophyllide. Photosynth. Res. 68, 131-139.

Gaubier, P., Wu, H.-J., Laudie, M., Delseny, M., and Grellet, F. (1995). A Chl synthetase gene from Arabidopsis thaliana. Mol. Gen. Genet. 249, 58-64.

Griffiths, W. T. (1991). Protochlorophyllide photoreduction. In: 
Chlorophylls, H. Scheer, ed. (Boca Raton, USA: CRC Press, Inc.), pp. 433-450.

Helfrich, M. (1995). Chemische Modifikation von ChlorophyllVorstufen und deren Verwendung zur Charakterisierung von Enzymen der Chlorophyll-Biosynthese. Ph.D. Thesis, University of Munich, Germany.

Helfrich, M., Schoch, S., Lempert, U., Cmiel, E., and Rüdiger, W. (1994). Chlorophyll synthetase cannot synthesize chlorophyll a'. Eur. J. Biochem. 219, 267-275.

Helfrich, M., Schoch, S., Schäfer, W., Ryberg, M., and Rüdiger, W. (1996). Absolute configuration of protochlorophyllide $a$ and substrate specificity of NADPH-protochlorophyllide oxidoreductase. J. Am. Chem. Soc. 118, 2606-2611.

Holt, A. S., and Morley, H. V. (1959). A proposed structure for chlorophyll d. Can. J. Chem. 37, 507-514.

Jones, I. D., White, R. C., Gibbs, E., and Butler, L. S. (1977). Estimation of zinc pheophytins, chlorophylls, and pheophytins in mixtures in diethyl ether or $80 \%$ acetone by spectrophotometry and fluorometry. Agric. Food Chem. 25, 146-149.

Keller, Y., Bouvier, F. D., and Harlingue, A. (1998). Metabolic compartmentation of plastid prenyllipid biosynthesis: evidence for the involvement of a multifunctional CHL P. Eur. J. Biochem. 251, 413-417.

Klement, H., Helfrich, M., Schoch, S., Oster, U., and Rüdiger, W. (1999). Pigment-free NADPH:protochlorophyllide oxidoreductase from Avena sativa L.: purification and substrate specificity. Eur. J. Biochem. 265, 862-874.

Kral, A. M., Diehl, R. E., deSolms, S. J., Williams, T. M., Kohl, N. E., and Omer, C. A. (1997). Mutational analysis of conserved residues of the $B$-subunit of human farnesyl: protein transferase. J. Biol. Chem. 272, 27319-27323.

Kyhse-Andersen, J. (1984). Electroblotting of multiple gels: a simple apparatus without buffer tank for rapid transfer of proteins from polyacrylamide to nitrocellulose. J. Biochem. Biophys. Methods 10, 203-209.

Lebedev, N., and Timko, M. P. (1998). Protochlorophyllide photoreduction. Photosynth. Res. 58, 5-23.

Lindsten, A., Welch, C. J., Schoch, S., Ryberg, M., Rüdiger, W., and Sundqvist, C. (1990). Chlorophyll synthase is latent in well preserved prolamellar bodies of etiolated wheat. Physiol. Plant. 80, 277-285.

Lopez, J. C., Ryan, S., and Blankenship, R. E. (1996). Sequence of the bxhG gene from Chloroflexus aurantiacus: relationship between chlorophyll synthase and other polyprenyltransferases. J. Bacteriol. 178, 3369-3373.
Oster, U., and Rüdiger, W. (1997). The G4 gene of Arabidopsis thaliana encodes a chlorophyll synthase of etiolated plants. Bot. Acta 110, 420-423.

Oster, U., Bauer, C. E., and Rüdiger, W. (1997). Characterization of chlorophyll a and bacteriochlorophyll a synthases by heterologous expression in Escherichia coli. J. Biol. Chem. 272, 9671-9676.

Melzer, M., and Heide, L. (1994). Characterization of polyprenyldiphosphate:4-hydroxybenzoate polyprenyltransferase from Escherichia coli. Biochim. Biophys. Acta 1212, 93-102.

Pennington, F. C., Strain, H. H., Svec, W. A., and Katz, J. J. (1964). Preparation and properties of pyrochlorophyll a, methyl pyrochlorophyllide a, pyropheophytin a, and methyl pyropheophorbide a derived from chlorophyll by decarbomethoxylation. J. Am. Chem. Soc. 86, 1418-1426.

Porra, R. J. (1991). Recent advances and re-assessments in chlorophyll extraction and assay procedures for terrestrial, aquatic, and marine organisms, including recalcitrant algae. In: Chlorophylls, H. Scheer, ed. (Boca Raton, USA: CRC Press, Inc.), pp. 31-57.

Schmid, H. C., Oster, U., Kögel, J., Lenz, S., and Rüdiger, W. (2001). Cloning and characterisation of chlorophyll synthase from Avena sativa. Biol. Chem. 382, 903-911.

Schoch, S. (1978). The esterification of chlorophyllide a in greening bean leaves. Z. Naturforsch. 33, 712-714.

Schoch, S., Lempert, U., and Rüdiger, W. (1977). Über die letzten Stufen der Chlorophyllbiosynthese: Zwischenprodukte zwischen Chlorophyllid und phytolhaltigem Chlorophyll. Z. Pflanzenphysiol. 83, 427-436.

Soll, J., Schultz, G., Rüdiger, W., and Benz, J. (1983). Hydrogenation of geranylgeraniol: two pathways exist in spinach chloroplasts. Plant Physiol. 71, 849-854.

Tarshis, L. C., Proteau, P. J., Kellogg, B. A., Sacchettini, J. C., and Poulter, C. D. (1996). Regulation of product chain length by isoprenyl diphosphate synthases. Proc. Natl. Acad. Sci. USA 93, 15018-15023.

Voet, D., and Voet, J. G. (1990). Biochemistry (New York, USA: Wiley \& Sons, Inc.), p. 348.

Wang, K., and Ohnuma, S. (1999). Chain-length determination mechanism of isoprenyl diphosphate synthases and implications for molecular evolution. Trends Biochem. Sci. 24, $445-451$

Received February 6, 2002; accepted April 24, 2002 